\title{
Mão na massa e skate no pé: práticas citadinas nas novas centralidades paulistanas
}

Skate and Create: the practice of skateboarding in the new centralities of São Paulo

\section{Giancarlo Marques Carraro Machado}

\section{(2) OpenEdition}

Edição electrónica

URL: http://journals.openedition.org/aa/3523

DOI: $10.4000 /$ aa. 3523

ISSN: 2357-738X

\section{Editora}

Programa de Pós-Graduação em Antropologia Social (UnB)

\section{Edição impressa}

Data de publição: 1 junho 2019

Paginação: 285-305

ISSN: 0102-4302

\section{Refêrencia eletrónica}

Giancarlo Marques Carraro Machado, «Mão na massa e skate no pé: práticas citadinas nas novas centralidades paulistanas», Anuário Antropológico [Online], v.44 n.1 | 2019, posto online no dia 06 julho 2019, consultado o 28 abril 2021. URL: http://journals.openedition.org/aa/3523 ; DOI: https://doi.org/ $10.4000 /$ aa. 3523

\section{(c) $(1)(9)$}

Anuário Antropológico is licensed under a Creative Commons Atribuição-Uso Não-Comercial-Proibição de realização de Obras Derivadas 4.0 International. 


\title{
Mão na massa e skate no pé: práticas citadinas nas novas centralidades paulistanas ${ }^{1}$
}

\author{
Giancarlo Marques Carraro Machado \\ Universidade Estadual de Montes Claros - Brasil
}

\section{Introdução: manobras citadinas}

A prática do skate de rua não se circunscreve apenas a imponentes espaços públicos que toleram uma confluência de experiências citadinas, a regiões onde ocupações populares são patentes, a equipamentos urbanos obsoletos e degradados e tampouco a contextos periféricos marcados por certas limitações urbanísticas. Ela ocorre na medida em que os picos - termo nativo que designa equipamentos urbanos (bancos, escadas, corrimãos etc.) onde são realizadas as manobras dos praticantes - são descobertos, utilizados e apropriados ${ }^{2}$.

Como os rolês ${ }^{3}$ para tais fins são intermitentes, a coexistência de disputas, negociações, subversões e intervenções se faz presente de maneira regular em incontáveis espaços da cidade, inclusive em áreas enobrecidas onde a presença, circulação e manobras dos skatistas são consideradas como incabíveis e, por vezes, repugnantes $^{4}$. É o que acontece, por exemplo, no quadrante sudoeste paulistano, sobretudo nas três principais avenidas que compõem as novas centralidades da cidade: Avenida Paulista, Avenida Faria Lima e Avenida Berrini ${ }^{5}$.

As avenidas em questão são gerenciadas a partir dos anseios que emergem da associação e disputas entre grupos corporativos, instituições privadas e poderes públicos. Além de se constituírem como importantes centros financeiros, elas também são marcadas por muitas atrações, empreendimentos empresariais e ofertas de serviços. Ao longo de suas extensões e redondezas é possível encontrar museus, bares, cinemas, restaurantes, shoppings, clubes, estações de metrô, além de majestosas edificações verticais que abrigam sedes de bancos, empresas multinacionais e demasiados escritórios e salas comerciais. Os seus planejamentos foram assinalados por estratégias neoliberais com vistas a atender as demandas das centralidades das quais fazem parte. Em razão disso, as avenidas tiveram as suas condições arquitetônicas e urbanísticas remodeladas a fim de assegurar segurança, limpeza e ordenamento espacial em seus limites. Essas prioridades ficam evidente em recentes políticas urbanas, como nas propostas de suas propagadas revitalizações.

A que ocorreu na Avenida Faria Lima, por exemplo, é prova dessa constatação. 
Anunciada pela prefeitura de São Paulo em 2012, a iniciativa visava trazer uma série de melhorias estruturais para o local, como acessibilidade, iluminação, padronização das calçadas e dos mobiliários urbanos. O croqui das intervenções deixava claro que os objetivos do projeto de renovação urbana seriam: 1) requalificar a paisagem urbana; 2) ordenação do espaço público; 3) valorizar a circulação de pessoas ${ }^{6}$. Portanto, com base naquilo que fora divulgado, é possível perceber que este mais novo embelezamento estratégico da cidade objetivava, dentre outros anseios, alterar a paisagem de modo a priorizar sobretudo a circulação de pessoas, e não tanto as apropriações que elas fazem de seus espaços. Por conta dessas intenções, como nos lembra Frúgoli Jr. (2000: 21),

[...] é necessário atentar para a diferença que há entre premissas e intenções de determinados projetos urbanos e suas realizações concretas, já que a complexidade da conexão entre as intenções técnicas e as decisões políticas pode resultar em diversas formas de exclusão social, mesmo dentro de projetos, a princípio, igualitários.

Ao partir dos pressupostos de Zukin (2000), é possível considerar que as avenidas Paulista, Faria Lima e Berrini se transformaram, com efeito, em paisagens de poder, ou seja, em paisagens marcadas por uma estética sintomática de certas pretensões políticas e econômicas. Por esse ângulo, conforme assinalado por Rolnik e Frúgoli Jr. (2001), a implementação das novas territorialidades provocou deslocamentos de setores populares bem como um gradativo desaparecimento de espaços públicos articulados a um forte modelo de exclusão territorial. A fim de priorizar práticas de consumo, valorização de imóveis e circulação de capitais, as avenidas foram constituídas por diversos enclaves fortificados (Caldeira, 2000) detentores de uma série de dispositivos de controle que demarcam fronteiras físicas e simbólicas e que provocam impactos nos usos e nas apropriações citadinas de seus espaços.

As paisagens das avenidas Paulista, Faria Lima e Berrini, as quais são gerenciadas como meras mercadorias, tentam mascarar desigualdades, segregações, violências e assimetrias de poder, condições que limitam o direito à cidade a determinados setores da população. Os "parceiros da exclusão", denominação proposta por Fix (2001) para designar as articulações entre capital e Estado que orientam certas políticas urbanas, vêm agindo nestes locais de modo a obliterar - e até mesmo reprimir - características fundamentais da vida citadina em prol da manutenção dos anseios do mercado imobiliário, do capital financeiro e de demais lógicas de 
consumo. Dessa forma são criados diversos mecanismos para normatizar e ordenar as ocupações que se processam nas avenidas, a fim de manter uma coerência visual e espacial e um ambiente acolhedor sobretudo para profissionais do setor terciário, consumidores, turistas e grupos sociais mais privilegiados. Por conseguinte, são estabelecidos usos, funções, marcadores sociais e moralidades tidas como mais aceitáveis, ao passo que as que não se encaixam nas estratégicas pretensões são tratadas como desviantes, indisciplinadas e marginais e que por isso devem ser combatidas por estarem fora do lugar.

O combate contra aqueles considerados fora do lugar cotidianamente acontece nas paisagens de poder das centralidades paulistanas, no entanto, a sua ocorrência não reverbera que as estratégias empregadas em prol de comportamentos disciplinados e de uma civilidade consumista estejam sendo bem-sucedidas. Por mais que haja toda sorte de dispositivos de controle espalhados pelas avenidas Paulista, Faria Lima e Berrini, eles ainda assim não são suficientes para conter a presença daquelas pessoas que, sob certas óticas, são consideradas indesejáveis. Moradores e artistas de rua, crianças pedintes, jovens arruaceiros, vendedores ambulantes, hippies, pichadores e grafiteiros, usuários de drogas ilícitas, assaltantes etc.: por meio de um olhar de perto e de dentro (Magnani, 2002) é possível constatar a assiduidade destes e de muitos outros citadinos que embaralham certos ordenamentos espaciais e moralidades públicas. Por meio do vernacular (Zukin, 2000: 106), eles resistem às restrições estruturais e às premissas esperadas pelos agentes e instituições responsáveis pelos gerenciamentos das avenidas e, mesmo desprovidos de poder, criam uma tensão que incomoda certas imposições que lhes são destinadas.

A prática do skate, conforme já adiantado no início desta introdução, também se faz presente com veemência nestes espaços enobrecidos de São Paulo. Embora as paisagens de poder estratifiquem atividades e dinâmicas relacionais, os skatistas se preocupam em ocupá-las em razão de suas centralidades na cidade, das experiências e desafios que elas propiciam e sobretudo por conta das tessituras de seus equipamentos urbanos: bordas e quinas de mármore e granito, corrimãos de inox e metal, bancos de madeira, calçadas de concreto armado etc. Estas condições materiais são atrativas, pois possibilitam maior velocidade e deslize aos skates, além de controle rítmico mais apurado aos corpos dos praticantes.

Ao levar em conta tais considerações, este artigo se propõe a analisar, a partir de etnografias realizadas entre 2013 e 2016, os impactos da prática do skate de rua nos limites das novas centralidades paulistanas. Será considerada, à vista disso, uma 
análise situacional ${ }^{7}$ a fim de compreender a citadinidade em processo e a sua relação com eventuais normatizações tão caras ao gerenciamento urbano promovido pela parceria público-privada sintomática de políticas de cunho neoliberal. Com efeito, demonstrarei como jovens citadinos questionam premissas que permeiam lugares próprios (Certeau, 2009) marcados por esperadas univocidades e estabilidades por meio de suas artimanhas, percepções, maneiras e experiências e contribuem, assim, para a redefinição do espaço enquanto um lugar praticado (Idem, 2009) com a apregoação de novas leituras e valores simbólicos.

\section{A prática do skate nas paisagens de poder}

No decorrer do trabalho de campo, tive a oportunidade de acompanhar detidamente a prática do skate nas avenidas Paulista, Faria Lima e Berrini. Conforme averiguado etnograficamente, a inserção dos skatistas em cada uma delas ocorre de múltiplas maneiras, a depender de suas aspirações individuais, de seus níveis técnicos, de seus marcadores sociais de diferenças (gênero, classe, raça etc.), do número de pessoas envolvidas, das relações estabelecidas, das artimanhas que acionam nas situações que participam, e do tempo e dos espaços que ocupam. Cada sessão de skate é inigualável ${ }^{8}$; todavia, mesmo diante um rol de particularidades, é possível traçar considerações gerais que permitem problematizar o exercício de sua prática nas paisagens de poder paulistanas.

O primeiro aspecto a ser assinalado diz respeito ao momento em que a prática do skate se tornou regular e ganhou visibilidade em cada uma delas. Os incontáveis picos presentes nas extensões das avenidas são alvos dos skatistas desde a década de 1990, no entanto, a frequência de seus rolês não era tão evidente em razão de uma condição urbanística trivial: muitas calçadas eram revestidas por pedras portuguesas, material que dificulta a circulação das rodinhas dos skates e, consequentemente, a realização de manobras nos lugares skatáveis nelas dispostos. Mas, para o agrado dos praticantes, nos últimos anos todas as avenidas abordadas tiveram uma reformulação significativa de suas calçadas. Elas foram padronizadas e cobertas por pisos de concreto armado, logo, as suas condições urbanísticas passaram a favorecer os rolês em seus respectivos limites. Com a finalização dos reparos, os quais se deram em momentos distintos, não tardou para que as avenidas se tornassem alvo de skatistas oriundos de diversas partes da metrópole. O skatista profissional Klaus Bohms, ao comentar as reformulações, enfatiza que: 
Sem dúvida que as reformas que a gente viu no chão das calçadas da Paulista, Faria Lima e vários outros lugares da cidade melhoram a prática do skate na cidade. Mas além da prática do skate, melhora a vida do transeunte em geral. Mesmo sem skate as pessoas andam por um chão menos perigoso, não tem buraco, não tem pedra. E por mais que tenha pontos negativos por ter tantos skatistas misturados com as pessoas que estão andando a pé, pelo motivo de algum acidente leve, o skate escapar e bater na canela de alguém, às vezes acontece. Mas o ponto positivo é muito maior, porque a cidade tem muita gente praticando atividades ao ar livre, gente andando de bicicleta, andando de skate, isto dá uma energia a mais para a cidade. A gente vê uma cidade mais viva, as pessoas se divertindo, usando o espaço público como ele deveria ser usado como se fosse um quintal de todo mundo, e não apenas como um espaço de passagem (Klaus Bohms, skatista profissional, depoimento concedido ao Programa Olho de Peixe. Disponível em: http: / /www. programaolhodepeixe.com/site/avenida-faria-lima/. Acesso em: 11 ago. 2016).

Bastou, portanto, a troca dos pisos das calçadas para que as paisagens das centralidades paulistanas ganhassem considerável relevo no universo do skate. As principais revistas especializadas destacaram as suas importâncias. A revista CemporcentoSkate, por exemplo, ao se referir à Avenida Faria Lima enfatizou que "após a finalização de obras nas calçadas e implantação de ciclovia no canteiro central, a Av. Faria Lima

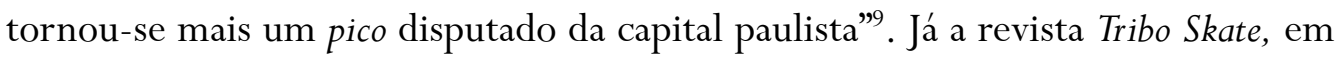
matéria especial sobre a Avenida Paulista, enalteceu que

[...] um lugar onde a pedra portuguesa reinou por quase 40 anos, e depois de um ano de interdições e transtornos fora do comum, se tornou o sonho de qualquer ser levemente racional que já pisou em um skate alguma vez na vida. São bordas de mármores de todos os tamanhos, escadas, wallrides, gaps, hidrantes, buracos. Tudo cercado por um chão liso, melhor do que da maioria das pistas da cidade. A simples sensação de atravessar os largos quarteirões remando é indescritível ("O passeio nosso de cada dia”. Revista Tribo Skate, n. 161, 2009).

Outra característica que marca as avenidas diz respeito à quantidade de picos situados próximos uns aos outros, a qual é superior ao observado em outras partes da cidade. Como elas detêm melhores condições urbanísticas, os skatistas podem circular pelas largas calçadas e utilizar variados obstáculos em sequência e de maneira ininterrupta. Isso faz com que as suas linhas, isto é, a sucessão de manobras, se tornem mais fluidas, diversificadas e extensas. O skatista profissional Murilo Romão, por exemplo, foi protagonista de uma parte divulgada no filme intitulado 
CityZen ${ }^{10}$, em que faz um rolê utilizando dezenas de obstáculos dispostos ao longo de toda a Avenida Paulista. O seu intuito foi mostrar as potencialidades do local para a prática do skate e, para isso, teve a proeza de realizar manobras de uma extremidade a outra, desde a Praça Oswaldo Cruz até a esquina com a Rua da Consolação.

A partir da gestão do prefeito Fernando Haddad (PT, 2012-2016), Paulista, Faria Lima e Berrini foram contempladas com significativos trechos de ciclovias. A qualidade de seus pisos tornou-se propícia não apenas para bicicletas, mas também para a circulação de skates. Com as suas instalações, muitos praticantes passaram a utilizá-las, como é o caso dos adeptos do longboard e cruiser, tipos de skates que permitem melhor mobilidade em virtude de suas rodas maiores e mais macias. Os adeptos do street skate, modalidade que constitui o foco do artigo, também utilizam as ciclovias, entretanto, é mister reiterar que as suas preferências ainda assim se concentram nas calçadas. O motivo para tanto é óbvio: as ciclovias geralmente apresentam um desenho mais uniforme e contam com poucos picos, ao passo que as calçadas estão repletas de obstáculos que instigam a apropriação e a realização de manobras.

Apesar da plasticidade dos corpos em interação com as paisagens, a rápida circulação dos skatistas por entre os picos é alvo de muitas reprovações por parte de transeuntes que caminham pelas calçadas: xingamentos, reclamações e olhares raivosos foram algumas das reações observadas. A possibilidade de choques é iminente, dado os diferentes ritmos em voga, portanto, cabe ao praticante ter técnica, equilíbrio e atenção apurada, a fim de evitar eventuais solavancos que culminem em lesões entre os envolvidos. Malgrado os cuidados de alguns e a imprudência de outros, a ocorrência de dissabores envolvendo skatistas é evidente, visto que as calçadas são marcadas por considerável fluxo de pessoas que andam a pé disputando a inserção e a locomoção pelos seus espaços.

Os picos situados nas avenidas estão dispostos em dois tipos de espaços: em espaços públicos (calçadas, praças, pontos de ônibus, estações de metrô etc.), onde os skatistas conseguem permanecer por mais tempo; e em espaços privados (fachadas de bancos, de empreendimentos empresariais, de prédios residenciais, de galerias comerciais, dentre outros), sendo estes permeados por dispositivos de vigilância e por regras de acessibilidade.

Quanto aos espaços públicos, na avenida Paulista há algumas áreas que são reconhecidas como pontos de encontro de skatistas, dentre elas, Praça do Ciclista, Praça Oswaldo Cruz e as calçadas situadas em frente a Caixa Econômica Federal (prédio entre as estações Consolação e Trianon-MASP do metrô). A frequência de skatistas 
nesses locais é usual em dias úteis e principalmente aos finais de semana. Mas aos domingos, quando há o fechamento da avenida para carros e a sua abertura para pedestres, é quando se dá a ocupação mais expressiva ${ }^{11}$. É nesse dia específico que os skatistas aproveitam para andar de skate sem tantas preocupações, visto que há menor possibilidade de repressão, conflitos e aborrecimentos. As suas manobras tornam-se, com efeito, mais uma atração artística do local:

O skate toma na Paulista um aspecto meio artista de rua. Têm as bandas, os caras que imitam o Michael Jackson e têm os skatistas. Muitas vezes tem gente que para para tirar foto. A galera para para nos ver andando (Filipe Maia, skatista amador e jornalista, entrevista em 2016).

Na avenida Faria Lima, por sua vez, os espaços de referência são Largo da Batata e Beco do Valadão ${ }^{12}$. Ambos, sobretudo este último, concentram a presença de skatistas em diferentes horários e dias da semana. Já a Avenida Berrini, ao contrário das demais, ainda não possui uma área específica que seja reconhecida por comportar cotidianamente as suas experiências corporais e relacionais. Em todas as avenidas, os skatistas conseguem, portanto, se inserir nos espaços públicos e realizar as suas manobras nas brechas encontradas em meio ao intenso trânsito de pessoas nas calçadas. As repressões à prática eventualmente acontecem quando policiais ou guardas metropolitanos resolvem cessá-la amparados na justificativa de que os praticantes correm o risco de atropelar e machucar transeuntes, sobretudo idosos, ou quando moradores, síndicos de prédios ou trabalhadores locais os acionam para conter barulhos excessivos ou certas algazarras promovidas que se destoam das moralidades esperadas para as paisagens de poder paulistanas.

Os picos situados nas fachadas de espaços privados também são utilizados pelos skatistas. Eles são os mais desejados em virtude de suas qualidades materiais, entretanto, as apropriações que deles são feitas se dão apenas em situações esporádicas e por determinado perfil de praticante (geralmente amadores e profissionais detentores de excelência técnica). As fachadas, como já fora indicado, são permeadas por uma série de dispositivos que visam controlar o acesso ao interior de prédios e demais tipos de estabelecimentos. Câmeras, alarmes, grades, equipe de seguranças são posicionadas a fim de vigiar e conter as apropriações indesejáveis que atrapalham os propósitos esperados por cada empreendimento. Todas essas e outras barreiras dificultam a realização da prática do skate, todavia, mesmo assim há skatistas 
dispostos a desafiá-las a fim de conseguirem acertar as suas respectivas manobras ${ }^{13}$. A possibilidade de repressão, principalmente por parte dos seguranças que zelam pelas propriedades, é inegável. Basta o barulho das rodinhas e o estalar das madeiras dos skates nos limites das fachadas para que eles rapidamente entrem em ação.

Na Faria Lima e Berrini eu sinto repressão. Os seguranças vêm babando. Por ser bastante comercial, prédios privados, a repressão não é nem policial, mas de segurança. A liberdade que você tem na Paulista para andar é diferente da que você tem na Faria Lima. A Faria Lima é menos ponto turístico, é menos amigável ao público. Mas é um público com mais grana, a galera tem mais receio do skatista (Filipe Maia, skatista amador e jornalista, entrevista em 2016).

Consoante ao presenciado, alguns seguranças fazem abordagens que prezam pelo diálogo e pelo entendimento com os skatistas, ao passo que também há aqueles que não medem esforços para enquadrá-los com certa truculência, por vezes com violência física. Para se desvencilharem das eventuais negações ou embates, os praticantes adotam uma série de táticas que visam superar as regras de controle dos espaços onde se situam os picos, quais sejam, tentar ocupá-los em horários em que a movimentação de pedestres não seja tão intensa, não envolver muitos participantes em uma sessão para não chamar a atenção dos seguranças e combinar de antemão as reações que tomarão, caso sejam repreendidos.

De acordo com a perspectiva dos skatistas contatados, as avenidas Faria Lima e Berrini (sobretudo esta última) são os locais da cidade onde há maior possibilidade de repressão. As sessões realizadas em seus picos são permeadas por desafios, logo, a depender de quais sejam eles, é necessário acionar outras táticas ainda mais astuciosas. O skatista profissional Luiz “Apelão”, por exemplo, esteve na Avenida Berrini, sem portar seu skate, apenas para mapear os picos disponíveis e para estudar a melhor maneira de utilizá-los. Após isso, ele retornou ao local para deixar as suas marcas em diversos equipamentos, muitos deles situados em fachadas de propriedades privadas. A sua artimanha, tal como frisa abaixo, foi eficaz:

Eu fui uns dias antes lá, analisar os picos, perguntar até que horas funcionava. Fui sem skate, tirei fotos dos picos. Perguntei se abria de domingo, se tinha segurança, essas coisas. Tinha um pico lá que andei, que é uma transição, este pico é muito proibido. Mas eu dei sorte de ter conseguido andar nele. Mas a maioria da galera que vai nele, tenta uma, duas, três vezes no máximo e já embaça. Quando eu gravei foi num domingo. É o único dia que dá (Luiz “Apelão”, skatista profissional, entrevista em 2016). 
Outra situação que chamou a atenção do decorrer do trabalho de campo foi a espera ansiosa dos skatistas pelos jogos da seleção brasileira de futebol durante a Copa do Mundo de $2014^{14}$. Nesses instantes específicos, aproveitando-se do esvaziamento das avenidas e das atenções voltadas às partidas futebolísticas, vários deles puderam andar em picos situados em propriedades privadas que são demasiadamente vigiadas. Foram, segundo os interlocutores, chances únicas para se apropriarem de alguns dos obstáculos mais cobiçados de São Paulo.

Assim sendo, as apropriações de picos situados em espaços privados comumente acontecem de maneira rápida. Nesses casos, o que está em jogo não é apenas a qualidade das manobras, mas também a superação das proibições impostas. São essas conquistas que fazem um rolê ser bem-sucedido:

O ponto positivo é que a avenida é lisa do começo ao fim. Então você consegue andar sem parar nela. E também tem vários picos para parar e mandar manobras. O ponto negativo é que é um lugar de prédios comerciais, é passagem de gente o tempo inteiro. E por serem prédios comerciais, eles seguem a norma de não deixar ninguém andar de skate na frente daquela calçada, eles se responsabilizam pela fachada do lugar. Mas ambos os pontos negativos a gente consegue burlar e se divertir com isto. De usar a criatividade para achar um lugar que não é tão perfeito, mas que a gente consegue se divertir. Então no final das contas é apenas ponto positivo. Porque também não dá para ter apenas pontos negativos: de ser tudo liberado para andar e que não tenha gente, porque aí a gente está querendo um skatepark, né? A diversão é ter os pontos negativos e a gente saber lidar com eles (Klaus Bohms, skatista profissional, depoimento concedido ao Programa Olho de Peixe. Disponível em: http://www.programaolhodepeixe.com/site/avenida-faria-lima/. Acesso em: 11 ago. 2016. Grifos meus).

A fim de registrarem as situações em que estão inseridos, os skatistas envolvidos numa sessão prezam pela captação de imagens, em fotos ou vídeos, que são utilizadas com diversos fins, sejam eles pessoais ou profissionais ${ }^{15}$. Essa é uma forma de comprovar a conquista de picos situados em paisagens de poder da cidade, as sucedidas táticas diante dos dispositivos de controle nelas contidos, além da realização da manobra por meio da qual é evidenciado o nível técnico do praticante. Vale ressaltar que câmeras e filmadoras contribuem para mediar relações ou minar certos conflitos estabelecidos com os agentes responsáveis pela vigilância dos espaços, como seguranças, policiais e guardas metropolitanos. Em alguns casos, como já demons- 
trado em outras pesquisas (Machado, 2014; 2017), os skatistas - eventualmente em companhia de fotógrafos e videomakers -, quando em sessão em equipamentos que não foram planejados para a prática do skate, podem argumentar que não estão ali para se divertir, fazer algazarra e tampouco destruí-los, mas, ao contrário, por conta de um trabalho artístico (expresso por meio da captação de imagens) que poderá ser publicado na mídia especializada.

Essa tática às vezes é bem-sucedida, todavia, as proibições - e, em alguns casos, as truculências - são mais corriqueiras posto que o skate, conforme já evidenciado, quando praticado fora das pistas, não raro é associado ao vandalismo, a uma prática marginal que polui e danifica os espaços e equipamentos urbanos.

Andar de skate na Faria Lima para mim é rolê para filmar. É para explorar picos que você já tem na mente. Vai para um pico e filma. Se for expulso, vai para outro pico. Mas não é para ficar. E a Berrini é pior ainda. É o espaço, com base na minha experiência de picos na cidade, é onde tive maior repressão de segurança, maior número de “nãos”. Da galera proibir a prática. É diferente, é muito prédio comercial (Filipe Maia, skatista amador e jornalista, entrevista em 2016).

Vale pontuar que os diversos conflitos já ocorridos nas paisagens de poder aqui elencadas reverberaram, inclusive, na tentativa de proibição da prática do skate nas calçadas de todo o território do município de São Paulo. Em 2009, o então vereador Adolfo Quintas (PSDB) formulou o Projeto de Lei n 116/2009 com a intenção de regulamentar tal medida coercitiva e restringir o uso de skates apenas a áreas reservadas para seu fim (como as pistas, por exemplo). A propositura não foi aprovada, no entanto, a sua mera criação reflete como as façanhas dos skatistas nas centralidades paulistanas são incômodas a ponto de se tornarem alvo de certas pretensões políticas $^{16}$.

Outras reações à prática do skate nas avenidas vêm se dando a partir de intervenções efetuadas por agentes ou instituições responsáveis pelos gerenciamentos das fachadas das propriedades privadas que resguardam picos muito utilizados pelos skatistas. Conforme constatado empiricamente, várias delas - como as situadas nas avenidas Paulista e Faria Lima, por exemplo - tiveram alterações significativas em suas condições arquitetônicas a fim de coibir especificamente a presença de skatistas e, de modo mais amplo, de outros citadinos indesejáveis. Algumas propriedades instalaram espetos de aço em quinas, substituíram pisos de texturas lisas por texturas rugosas, aumentaram o número de grades e barreiras de ferro, remodelaram o 
formato de bancos e outros equipamentos, enfim, instauraram uma série de dispositivos de seguranças hostis às pessoas. Tratam-se, portanto, de medidas estratégicas que visam anular as possibilidades dos skatistas considerarem certos equipamentos enquanto picos para as suas manobras. Um interlocutor frisa que

esse tipo de intervenção das propriedades eu acho mais efetivo, e mais brutal, pois você atua na estrutura arquitetônica da cidade em função de um grupo só. O skate é tão perturbador que você precisa mexer na sua estrutura para a galera parar de usar (Filipe Maia, skatista amador e jornalista, entrevista em 2016. Grifos meus).

Já para Murilo Romão, skatista profissional contatado, "eles [os responsáveis pelas fachadas] vão entendendo o skate aos poucos. Eles vão vendo onde a galera está andando mais". Em decorrência desse entendimento das pretensões dos skatistas, as paisagens de poder vêm reagindo de modo a fragmentar os espaços de suas fachadas a partir da acentuação de uma série de transformações arquitetônicas. Com efeito, os usos citadinos são preteridos em prol das lógicas aventadas pelos "parceiros da exclusão" que almejam controlar as apropriações das principais avenidas do quadrante sudoeste. Os skatistas tentam se esquivar dessas demarcações, por mais restritivas que sejam, e por meio de seus impulsos fugazes e de suas manobras deslizantes e giratórias, eles instauram contra-usos dos espaços (Leite, 2007), ou seja, reações diversas que ganham a conotação de uma tática simbólica de contestação e afrontamento. Posto isso, concordo com Howell (2001: 21), o qual salienta que "a prática do skate é a face do design defensivo; não é um ataque à arquitetura de exclusão, mas, de fato, um sintoma, um componente irredutível de tal arquitetura. Este é um relacionamento simbiótico e irreversível” (Tradução minha).

Ao criarem pontos de tensão, eles revelam não apenas as relações de poder a que se submetem, mas também como tais avenidas enobrecidas de São Paulo são permeáveis às suas façanhas. Os picos expõem as contradições que perpassam as brechas do público e do privado e comunicam o local ao global por meio das captações de imagens, das representações de seus espaços e equipamentos que são propagados intensamente pelos skatistas. Todavia, os skatistas não se deixam sucumbir pelas frivolidades do urbano, tampouco ao gerenciamento da cidade enquanto mercadoria. Eles clamam pelo direito de se apropriarem de todas as suas partes, inclusive de terem acesso às suas centralidades, em vez de se verem dispersos ou confinados em seus respectivos bairros e quebradas ${ }^{17}$. É o que se verá a seguir. 


\section{Mão na massa: a construção do Beco do Valadão}

Além da utilização dos vários picos que surgiram após a reformulação das calçadas da Avenida Faria Lima, os skatistas ainda se apropriaram de uma rua que lhe é paralela e transformaram todo o seu espaço com uma série de intervenções. $\mathrm{O}$ local em questão é a Rua Matias Valadão, a qual era demasiada curta, sem saída, e que por isto contava apenas com um ponto de táxi em seu interior. Em decorrência desses aspectos, com a revitalização da avenida, o seu asfalto foi coberto por concreto armado, logo, ela passou a estar no mesmo nível das calçadas, condição que a colocou enquanto uma extensão delas.

Livre de carros, com sombras e chão liso. Não custou para que diversos citadinos descobrissem a "nova” Rua Matias Valadão para deixarem nela as suas respectivas marcas. As paredes dos muros que a cercam receberam grafites e pichações. Motoboys que atuam na Avenida Faria Lima eventualmente utilizavam parte de seu espaço como estacionamento para motos. Já os skatistas fizeram do seu piso uma espécie de folha em branco que permite a inscrição de múltiplas técnicas corporais. Por se situar entre dois grandes prédios empresariais, a rua ganhou ainda a alcunha de Beco doValadão, forma como é chamada pelos interlocutores da pesquisa.

Para torná-lo mais atrativo, alguns praticantes resolveram colocar em seu interior alguns materiais encontrados ao longo da Avenida Faria Lima. Lixeiras, placas de trânsito, pedaços de madeira, blocos de concreto, banco de carro, cofre, enfim, tudo aquilo que era descartado, tido para muitos como lixo ou entulho, ganhava novas finalidades a partir da prática do skate. No entanto, algo que incomodava os skatistas era o fato de que a permanência desses obstáculos no beco nunca era definitiva. Da noite para o dia todos os seus investimentos e improvisações eram desmanchados por funcionários da prefeitura, policiais, guardas ou trabalhadores dos prédios do entorno. Era preciso, pois, resistir a fim de resguardar o espaço como um pico de skate.

Uma alternativa encontrada pelos frequentadores do Beco do Valadão foi a construção de obstáculos de concreto. Esta condição material os fixaria no chão e certamente dificultaria as suas retiradas por parte daqueles que tentavam coibir a prática do skate no local. O primeiro passo para tanto foi a instalação de um pequeno palco de cimento com cantoneira de ferro afixada em sua borda. O obstáculo permaneceu fixo no espaço, e os skatistas puderam utilizá-lo sem demais problemas. Ao perceberem a possibilidade, os frequentadores decidiram incrementar a construção de outros picos. Com o passar do tempo, foram feitas, então, novas construções: uma 
leve inclinação que interliga o chão e a parede (chamada pelos skatistas de wallride), um palco largo para manobras de equilíbrios (chamado de manual) e ainda um palco curto, porém maior em altura se comparado aos demais, com a superfície de mármore propícia para a realização de manobras de deslize.

A construção dos obstáculos no Beco do Valadão foi feita de maneira autônoma e sem a autorização do poder público. Por não contar com o apoio de terceiros, os próprios skatistas que frequentam a Avenida Faria Lima elaboraram táticas com vistas a angariar dinheiro para a compra dos materiais usados nas obras. A principal delas foi o rateio dos valores estimados entre os principais frequentadores do local. Para efetivar a construção e a reforma dos obstáculos, eles também criaram um grupo de mensagens no aplicativo WhatsApp. A partir de tal mecanismo, os skatistas combinavam rolês, agendavam as suas manutenções e compartilhavam demais informações pertinentes a tudo aquilo que acontecia no beco. Segundo informa Caíque Rodrigues, praticante amador oriundo da cidade de Taboão da Serra, cuja presença era assídua no local,

muitos moleques não estão trabalhando, ou a mãe não solta [o dinheiro], ou realmente não tem. Às vezes vêm de longe e só têm o dinheiro da passagem. Quanto à mão na massa, temos um grupo no WhatsApp, daí cola todo mundo com os materiais e mão na massa. E todo mundo faz. E a limpeza, fazemos direto. Direto a gente compra vassoura, rodo, pá e dura cinco dias. E some. Alguém rouba. Já tivemos problemas de roubarem o corrimão. Deixamos um acorrentado no poste, e sumiu. Um outro sumiu, mas depois apareceu. E vamos indo assim (Caíque Rodrigues, skatista amador e publicitário, entrevista em 2015).

Os skatistas agenciam a apropriação do Beco do Valadão por meio de uma série de atitudes, entretanto, elas não são suficientes para conter outros interesses visados para o local. O estabelecimento de food trucks é um deles. A venda de comidas de rua tornou-se uma febre em São Paulo. Inúmeros carros adaptados passaram a circular pela cidade para oferecer guloseimas e bebidas dos mais variados tipos, sendo muitas delas divulgadas sob o rótulo de gourmet. O crescimento de tal empreendimento influenciou a aprovação de um projeto de lei municipal que regulamenta não apenas as suas atividades, mas também a ocupação das ruas e demais espaços públicos pelos $\operatorname{carros}^{18}$. Nesse sentido, por agora se configurar como uma extensão das calçadas da Avenida Faria Lima, onde impera um intenso fluxo de pessoas, já era previsível que a Rua Matias Valadão passasse a ser disputada por empresários ligados 
ao ramo, os quais vêm conseguindo, por vias legais, a autorização para estacionar food trucks e comercializar seus respectivos produtos no local.

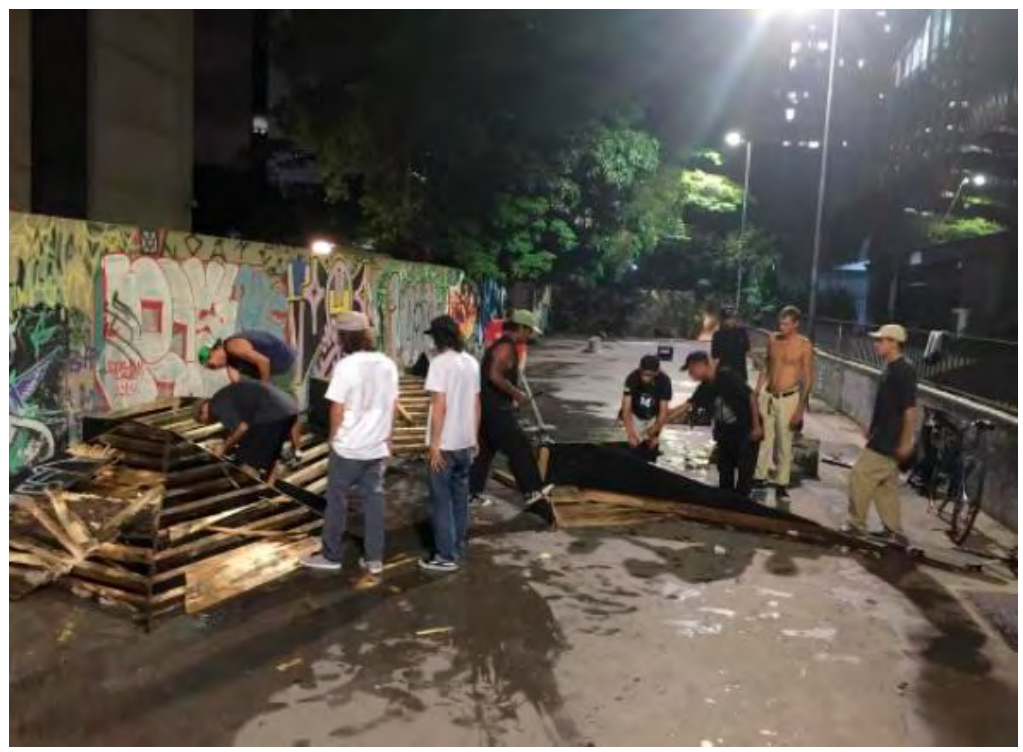

Imagem 1: Skatistas ajustam obstáculos no Beco do Valadão

(Disponível em: https://www.instagram.com/becodovaladao)

Muitos skatistas ficaram incomodados com a ocupação de food trucks que passou a ocorrer diariamente no mesmo espaço em que eles se reuniam. Em suas perspectivas, os carros estacionados e o afluxo de pessoas no local atrapalhariam a prática nos picos. Os responsáveis pelos empreendimentos, em contrapartida, se amparavam na autorização formal obtida para utilizar o espaço, logo, prezavam apenas em oferecer boas condições aos seus clientes. Essas diferentes lógicas de apropriação revelaram, destarte, certos conflitos. O interlocutor Caíque Rodrigues relatou a seguinte situação:

Um tempo atrás tivemos problemas com um dos donos dos food trucks. Ele vinha com uma van que tinha um engate, e ele estacionava nos fundos [do beco]. Aí [um pico] amanheceu com a pontinha do mármore quebrada. Daí fomos lá, conversamos com o cara, ele expôs a insatisfação com os skatistas. Ele disse que também tinha direito sobre o espaço, e que os caras não respeitavam, quando tinha cliente continuavam andando [de skate] (Caíque Rodrigues, skatista amador e publicitário, entrevista em 2015). 
A insatisfação era recíproca entre alguns skatistas e donos de food trucks. Os primeiros se posicionaram como protagonistas das transformações do Beco do Valadão, responsáveis por "dar vida” a uma área pouco utilizada da calçada, e que por isso também tinham o direito de se apropriarem quando e como bem entendessem do local. Contudo, a fim de evitar que os conflitos se potencializassem e prejudicassem a prática do skate, os skatistas se colocaram favoráveis ao estabelecimento de um consenso para a utilização do espaço:

Mas a gente explicou para ele [dono de um food truck] que a gente queria apaziguar a história, que fosse um lugar compartilhado, que pudesse ter tanto o food truck lá vendendo, quanto os skatistas lá andando. A gente falou que faria umas placas de conscientização. Aí o cara ajudou a pagar a reforma do pico (Caíque Rodrigues, skatista amador e publicitário, entrevista em 2015).

A partir de tais mediações os usos do Beco do Valadão passaram a ser menos conflituosos. Os skatistas grafitaram nas paredes algumas orientações que pregavam a convivência harmoniosa com os demais usuários do local. Além disso, estabeleceram que o horário ideal para a prática fosse após as 18 horas, ou seja, quando as atividades dos food trucks já estivessem finalizadas. Com efeito, em vez de disputar o espaço, chegou-se ao consenso de que ele seria compartilhado.

A revista Vice fez uma matéria intitulada "Um point de skatistas na Faria Lima foi tomado pelos food trucks" com a pretensão de abordar diferentes posicionamentos relacionados às situações ocorridas no beco ${ }^{19}$. Segundo a reportagem escrita pela jornalista Anna Mascarenhas, a indisposição entre skatistas e donos de food trucks parece ter sido fruto de uma estratégia criada por agentes ligados a prédios comerciais vizinhos à Rua Matias Valadão, os quais fizeram uma mobilização para que o local recebesse a instalação de um food park, iniciativa que contribuiria para gentrificar a área e, consequentemente, repelir a prática do skate. O supervisor administrativo do Edifício Conselheiro Paranaguá, imóvel vizinho ao espaço em questão, em depoimento à jornalista evidenciou que a proposta do food park "foi maravilhosa, principalmente por 'retirar o barulho e a bagunça' dos skatistas do local”. Ele acrescentou que "a Faria Lima é um cartão postal da cidade, não pode abrigar esse tipo de coisa” e que os frequentadores fazem diversas atividades na Rua Matias Valadão, como uso de drogas, sexo e até defecar. Por fim, quando questionado pela jornalista se ele já havia tentado um diálogo com os skatistas, o supervisor administrativo confessou que eles “são radicais... são jovens muito revoltados, não há diálogo", e 
que foram tentadas alternativas para barrar a prática do skate, como a solicitação para instalação de uma base da Polícia Militar ou da Guarda Civil Metropolitana.

Ao longo do trabalho de campo, conversei com skatistas e alguns deles levantaram a suspeita de que certas pessoas ligadas aos prédios também tentaram sabotar os picos construídos no BecoValadão. Esta constatação se deve a um fato que os deixou indignados. O mármore que compõe um dos principais obstáculos do local foi quebrado ao meio, no entanto, tal infortúnio não se deu pelo impacto das manobras realizadas, mas em razão de uma ação intencional provocada por alguém que dispunha de ferramentas específicas, como furadeira, pregos e martelo:

Desta vez agora, o mármore amanheceu quebrado ao meio. Só que você junta as peças, você nota que tem um furinho. Como se alguém viesse com uma furadeira ou um prego... Então vimos que fomos sabotados. Eu acho que foram os caras dos prédios. Com o food truck a gente teve este problema, mas a gente foi lá, conversou com o cara, e ele disse ter problema apenas com os skatistas que não respeitavam. Aí não tivemos mais problemas com os caras do food truck. Problema é com os prédios ao lado. Eles reclamam que em horário comercial não dá para trabalhar. Eu sinceramente acho que o barulho atrapalha, mas, você está na Faria Lima! O barulho que tem aqui de carro é ensurdecedor (Caíque Rodrigues, skatista amador e publicitário, entrevista em 2015).

A tentativa de arrebentar propositalmente o mármore foi em vão. Mesmo com o obstáculo danificado, os skatistas continuaram andando de skate no Beco doValadão, esse refúgio citadino em meio a uma paisagem de poder detentora de uns dos metros quadrados mais caros de São Paulo. Lá eles se reuniam, se mantinham visíveis numa área enobrecida e expunham as desigualdades e discriminações a que estavam sujeitos. E ainda trocavam experiências, estabeleciam formas de sociabilidade, faziam até churrascos e se dirigiam para outros picos das redondezas - como os localizados no Largo da Batata ou na extensão da Avenida Faria Lima - que integram um circuito skatista reconhecido no universo do skate como sendo característico da Zona Oeste paulistana.

\section{Considerações finais: quando os skatistas fazem a cidade}

O skate destrói, mas, de igual modo, também constrói a cidade. E ao moldarem e serem moldados por ela, os skatistas assinalam as marcas de suas experiências corporais e estéticas em equipamentos urbanos dos mais variados tipos, formas e 
tamanhos. Pouco importam as suas condições materiais, os locais onde estão dispostos e tampouco os dispositivos que regulam os seus usos. Os contratempos se convertem em obstáculos que devem ser superados astutamente, nem que para isso eventualmente tenham que fugir da polícia, enfrentar seguranças, negociar com donos de food trucks, desrespeitar síndicos de prédios e até colocar a mão na massa a fim de construir novos picos ou corrigir as imperfeições daqueles que padecem pela falta de manutenção.

Os skatistas embaralham a almejada convivência ordenada e põe em suspensão certos embelezamentos estratégicos de uma cidade gerenciada como mercadoria e voltada para práticas de cidadania que são englobadas sobretudo por lógicas de consumo. Enfim, muitas vezes eles recusam a cidade tal como ela é. Concordo com o pressuposto de Manuel Delgado (2008) que afirma que o espaço público é o âmbito do jogo, da alteridade generalizada, onde os praticantes da sociabilidade urbana parecem experimentar certo prazer em fazer cada vez mais complexas as regras do contrato social ocasional e constantemente renovado a que se comprometem, como se as negociações demorassem ao máximo a sua resolução, mantendo-se o maior tempo possível em estado de jogo. Essa generalização do jogo é, para tal autor, o que constitui a urbanidade, a qual, desse ponto de vista, produz e é produzida pelo street skate e por tantas outras práticas, discursos e representações.

A prática do skate estabelece, segundo Borden (2001), uma crítica performativa à forma como a cidade está consolidada. É pelos picos, portanto, que a cidade é desestabilizada e reinventada. Ela se torna um livro aberto e inconcluso para os skatistas, a partir do qual podem não apenas produzir interpretações, mas também deixar suas próprias marcas sobre aquilo que já está escrito.

Recebido: 24/01/2019

Aprovado: 26/04/2019 
Giancarlo Marques Carraro Machado é doutor em Antropologia Social pela Universidade de São Paulo (USP). É professor permanente do Programa de Pós-Graduação em Desenvolvimento Social da Universidade Estadual de Montes Claros (PPGDS/Unimontes-MG) e do Departamento de Ciências Sociais da mesma instituição. Pesquisador vinculado ao Núcleo de Antropologia Urbana da Universidade de São Paulo (NAU/USP). É autor do livro De carrinho pela cidade: a prática do skate em São Paulo (Intermeios/FAPESP, 2014). ORCID: 0000-0001-74049737. Contato: giancarlo.machado@unimontes.br

\section{Notas}

1. Este artigo é derivado da tese de doutorado $A$ cidade dos picos: a prática do skate e os desafios da citadinidade, defendida em 2017 no âmbito do Programa de Pós-Graduação em Antropologia Social da Universidade de São Paulo (PPGAS/USP) sob a orientação do Prof. Dr. José Guilherme Magnani. A pesquisa contou com financiamento da Fundação de Amparo à Pesquisa do Estado de São Paulo (FAPESP, processo 2012/23331-0).

2. Para uma discussão detida sobre a categoria pico, ver Machado (2014; 2017).

3. Role é uma categoria nativa. Trata-se de uma circulação pelos espaços urbanos a fim de propiciar a prática do skate.

4. Para outras análises sobre as repressões atribuídas à prática do skate quando realizada em áreas centrais, ver Humphreys (1997), Borden (2001) e Nolan (2003).

5. Segundo Frúgoli Jr. (2000: 25), as novas centralidades paulistanas, as quais se consolidaram em distintos momentos a partir do final da década de 1980, são cenários onde se articulam intervenções urbanas de caráter mais pontual, muito marcadas pela aliança entre interesses do capital e do poder público, tendo resultado, pois, "em processos marcados por práticas excludentes, já que, entre outras coisas, tais intervenções estão sobretudo norteadas pelo mercado, tendo como público preferencial as classes médias e altas".

6. Disponível em: <http://www.prefeitura.sp.gov.br/cidade/secretarias/subprefeituras/calcadas/index.php?p=37451>. Acesso em: 09 dez. 2015.

7. Ao levar em conta uma análise situacional, intento partir das recomendações de Michel Agier (2011: 73) tendo em vista uma melhor compreensão da citadinidade skatista: a) deslocar o ponto de vista da cidade para os citadinos; b) deslocar a problemática do objeto para o sujeito da questão, logo, em vez de considerar "o que é a cidade?", atentar para "o que faz a cidade?".

8. Termo nativo. Sessão é a prática do skate durante certo período de tempo.

9. "Faria Lima”. Disponível em: http://cemporcentoskate.uol.com.br/fiksperto/faria-lima. Acesso em: 09/08/2016.

10. O vídeo pode ser visualizado em: https: / / www.youtube.com/watch?v=aP3AudvX3PE.

11. O projeto Paulista Aberta, o qual fora sancionado pelo prefeito Fernando Haddad (PT) em 2016, legitimou ao menos durante um período específico de um dia da semana a ocorrência de práticas citadinas e de lazer ao longo da Avenida Paulista. 
12. As apropriações que são feitas do Beco do Valadão serão apresentadas no próximo tópico.

13. Os skatistas que ousam encarar picos situados em fachadas de propriedades privadas são, via de regra, detentores de níveis técnicos avançados, como amadores e sobretudo profissionais da modalidade street skate.

14. Tal constatação, na ocasião da etnografia realizada durante o período da Copa do Mundo de 2010, também fora assinalada em outra pesquisa de minha autoria (Machado, 2017).

15. A dinâmica em torno da captação de imagens por parte dos skatistas foi abordada em Machado (2014).

16. As implicações em torno desta tentativa de proibição do skate nas calçadas de São Paulo são abordadas em Machado (2014; 2017).

17. Termo nativo. Indicativo de localidade, geralmente utilizado para fazer referência a contextos periféricos da cidade de São Paulo.

18. Em 26 de dezembro de 2013, o prefeito Fernando Haddad (PT) sancionou a Lei ${ }^{\circ}$ 15.947/2013, que dispõe sobre as regras para comercialização de alimentos em vias e áreas públicas e dá outras providências. Mais informações em: http://www.capital.sp.gov.br/portal/noticia/2218\#ad-image-0.

19. MASCARENHAS, Anna. "Um point de skatistas na Faria Lima foi tomado pelos food trucks". Disponível em: http: / /www.vice.com/pt_br/read/um-point-de-skatistas-na-faria-lima-foi-tomado-pelos-food-trucks?utm_source=thumpfacebr. Acesso em: 30 dez. 2015.

\section{Referências bibliográficas}

AGIER, M. 2011. Antropologia da cidade: lugares, situações, movimentos. São Paulo: Terceiro Nome.

BORDEN, I. 2001. Skateboarding, space and the city: architecture and the body. Oxford: Berg.

CALDEIRA, T. P. R. 2000. Cidade de muros: crime, segregação e cidadania em São Paulo. São Paulo: EDUSP.

CEMPORCENTOSKATE. "Faria Lima”. Portal CemporcentoSkate. Disponível em: http://cemporcentoskate.uol.com.br/fiksperto/faria-lima. Acesso em: 09 ago. 2016.

CERTEAU, M. de. 2009. A invenção do cotidiano: artes de fazer. Petrópolis: Vozes, 16. ed.

CITYZEN. 2013. Direção: Guilherme Guimarães. Roteiro: Esteban Florio e Guilherme Guimarães. Brasil, 26 min.

DAMATTA, R. 1979. Carnavais, Malandros e Heróis. Rio de Janeiro: Zahar.

DELGADO, M. 2008. El animal público. Barcelona: Anagrama, 5. ed.

FIX, M. 2001. Parceiros da exclusão: duas histórias de construção de uma "Nova Cidade" em São Paulo: Faria Lima e Água Espraiada. São Paulo: Boitempo.

FRÚGGLI JR., H. 2000. Centralidade em São Paulo: trajetórias, conflitos e negociações na metrópole. São Paulo: Cortez / Edusp.

HOWELL, O. 2001. "The poetics of security: skateboarding, urban design, and the new public space”. Urban Action, p. 64-86.

HUMPHREYS, D. 1997. “Shredheads go mainstream? Snowboarding and alternative youth". Inter- 
national Review for the Sociology of Sport, v. 32, n. 2, p. 147-160.

LEITE, R. P. 2007. Contra-usos da cidade: lugares e espaço público na experiência urbana contemporânea. Campinas; Aracaju: Ed. Unicamp/Ed. UFS.

MACHADO, G. M. C. 2014. De “carrinho" pela cidade: a prática do skate em São Paulo. São Paulo: Intermeios/FAPESP.

MACHADO, G. M. C. 2017. A cidade dos picos: a prática do skate e os desafios da citadinidade. Tese [Doutorado em Antropologia Social], Faculdade de Filosofia, Letras e Ciências Humanas. Universidade de São Paulo, São Paulo.

MAGNANI, J. G. C. 2002. "De perto e de dentro: notas para uma etnografia urbana”. Revista Brasileira de Ciências Sociais, v. 17, n. 49, p. 11-29.

MAGNANI, J. G. C. 2012. Da periferia ao centro: trajetórias de pesquisas em Antropologia Urbana. São Paulo: Terceiro Nome.

MASCARENHAS, A. "Um point de skatistas na Faria Lima foi tomado pelos food trucks". Revista Vice. Disponível em: http://www.vice.com/pt_br/read/um-point-de-skatistas-na-faria-lima-foi-tomado-pelos-food-trucks?utmsource= thumpfacebr. Acesso em: 30 dez. 2015.

MUG, M. 2009. “Avenida Paulista: o passeio nosso de cada dia”. Revista Tribo Skate, n. 161.

NOLAN, N. 2003. "The ins and outs of Skateboarding and transgression in public space in Newcastle”. Australian Geographers, v. 34, n. 3, p. 311-327.

OLHO DE PEIXE. “Avenida Faria Lima”. Programa Olho de Peixe, 29/08/2014. Disponível em: <http://www.programaolhodepeixe.com/site/avenida-faria-lima/>. Acesso em: 11 ago. 2016. PREFEITURA DE SÃO PAULO. "Revitalização da Avenida Faria Lima tem acessibilidade e padronização de calçada”. Portal Prefeitura de São Paulo. Disponível em: http: / /www.prefeitura.sp.gov. $\mathrm{br} /$ cidade/secretarias/subprefeituras/calcadas/index.php?p=37451. Acesso em: 09 dez. 2015.

PREFEITURA DE SÃO PAULO. "Prefeito assina decreto que define regras para comida nas ruas da cidade”. Secretaria Executiva de Comunicação da Prefeitura de São Paulo. Disponível em: <http://www.capital.sp.gov.br/portal/noticia/2218\#ad-image-0>. Acesso em: 09 dez. 2015. ROLNIK, R; FRÚGOLI JR., H. 2001. "Reestruturação urbana da metrópole paulistana: a Zona Leste como território de rupturas e permanências”. Cadernos Metrópole, São Paulo, n. 6, p. 55-83. ZUKIN, S. 2000. "Paisagens urbanas pós-modernas: mapeando cultura e poder". In: ARANTES, Antonio A. (org.). O espaço da diferença. Campinas: Papirus. p. 80-103. 
Mão na massa e skate no pé: práticas citadinas nas novas centralidades paulistanas

Resumo: $O$ artigo analisa os impactos da prática do skate de rua nos limites das novas centralidades paulistanas. A partir de uma abordagem etnográfica será revelado como jovens citadinos questionam premissas que permeiam lugares próprios marcados por esperadas univocidades e estabilidades por meio de suas artimanhas, percepções, maneiras e experiências e contribuem, assim, para a redefinição do espaço enquanto um lugar praticado com a apregoação de novas leituras e valores simbólicos.

Palavras-chave: skate, citadinidade, cidade, espaços urbanos, antropologia urbana.
Skate and Create: the practice of skateboarding in the new centralities of São Paulo

Abstract: I examine how street skateboarders tactically resist certain urban planning and question some strategic embellishments of a metropolis managed by and for consumption interests. Thus, I contribute to urban anthropology studies by revealing how skateboarders - through their own perceptions, manners and experiences - creatively challenge the premises which permeate proper places marked by expected univocalities and stabilities.

Keywords: skateboarding, urbanity, city, urban spaces, urban anthropology. 